\title{
The Cross-border Connections. Emigrants, Immigrants and Their Homelands. Waldinger, Roger. Cambridge, Londres: Harvard University Press, 2015
}

\author{
Joan Lacomba \\ Universidad de Valencia \\ joan.lacomba@uv.es
}

Millones de personas se desplazan cada año desde un país a otro con el propósito de lograr una mejora en sus vidas. Este hecho aparentemente simple de explicar contiene una complejidad que en muchas ocasiones se pasa por alto. La migración se ha convertido en una de las principales claves explicativas del mundo globalizado y las sociedades que lo conforman. La movilidad de las personas por todo tipo de motivos es cada vez más acusada, y los intentos por cruzar fronteras para acceder a otros lugares donde lograr un mayor bienestar personal y familiar han pasado a constituirse en un notable desafío en su comprensión por las ciencias sociales. Pese a que la migración es catalogada habitualmente como un fenómeno histórico a través de los tiempos, o se tiende a destacar la "naturalidad" de la misma, quedan seguramente muchos aspectos pendientes que requieren de atención y mayor explicación. Las ciencias sociales no solo han presentado dificultades a la hora de explicar fenómenos no estáticos 0 enfrentarse a la movilidad, sino que el mismo carácter cambiante de la migración supone un reto a la hora de ofrecer una foto fija de la misma.

En el libro que nos ocupa, el sociólogo Roger Waldinger, profesor y director del Centro de Estudios de Migraciones de la Universidad de California Los Ángeles (UCLA), nos proporciona una lectura compleja de la migración, alejada de las concepciones binarias que tienden a simplificar un fenómeno cruzado por un sinfín de variables y situaciones que dificultan las generalizaciones y contradicen los estereotipos asociados frecuentemente al mismo. A lo largo del libro Waldinger retuerce y da la vuelta a buen número de las "evidencias" dadas por supues- tas por decisores políticos e investigadores de las migraciones, aportando una visión de mucha mayor complejidad en torno a las mismas. En sus páginas se propone también una forma más ajustada de entender la migración, mostrando cómo la mayor parte de los migrantes tratan de buscar el éxito siendo un poco de aquí y de allí ("sus hogares", como reza el subtítulo del libro), aprovechando las ventajas comparativas que puedan existir en uno y otro lado, algo que escapa a buena parte de los estudios de la migración, centrados bien en la emigración, bien en la inmigración. En ocasiones el diferencial existente entre uno y otro lado puede que no sea tan apreciable, 0 que no lo sea para el observador externo, pero pequeñas ventajas no sólo materiales, sino también simbólicas 0 en derechos 0 seguridad, pueden justificar plenamente la migración.

A través de sus páginas, Waldinger también nos recuerda algo que podría parecer obvio, y que sin embargo es frecuentemente obviado, como lo es el hecho de que los migrantes sean a un mismo tiempo emigrantes e inmigrantes. Tomando como eje de su argumentación esa doble condición de los migrantes (capítulos uno y tres), Waldinger trata de mostrar cómo cada una de las dos caras no puede ser entendida sin tener en cuenta la otra. De modo que, aunque frecuentemente se tiende a presentar a los migrantes como individuos que han salido de un país - al que se supone que abandonaron y donde dejaron un vacío - y que se han instalado en otro - en donde se da por supuesto que tratarán de echar raíces y adaptarse al nuevo medio-, en realidad la experiencia del emigrante no puede ser desgajada de la del inmigrante, un hecho que se acompaña de numerosas tensiones y conflictos. 
A partir de esta premisa, Waldinger realiza un amplio y detallado recorrido por las principales conexiones que la migración genera entre los lugares de origen y destino de la misma (capítulo 4), mostrándonos cómo los inmigrantes permanecen conectados de múltiples modos con sus sociedades de origen (incluso puede que ya existieran conexiones con el lugar de destino antes de la emigración), aunque para ello se centre en las conexiones y los cambios sociales y políticos, más que en aquellos otros de carácter cultural o económico. A su vez, Waldinger incide en que esas numerosas conexiones transfronterizas no solo no son nuevas, sino que tampoco van a permanecer inalteradas y tienen también sus límites, estableciendo así una de sus primeras diferenciaciones con los teóricos del transnacionalismo y los apologetas del influjo de las nuevas tecnologías. En este sentido, el autor insiste en que se ha incurrido en una cierta exageración (y no la única), dado que siempre habría existido la comunicación por unos medios u otros de los migrantes con sus lugares origen, aunque ésta pueda ser ahora instantánea y haber ampliado notablemente su alcance. Waldinger manifiesta su escepticismo en torno a esta cuestión, Ilegando a afirmar que "las continuidades encontradas en este largo período de tiempo histórico también excluyen la posibilidad de que los cambios contemporáneos en la tecnología de las telecomunicaciones hayan transformado las interacciones entre los emigrantes y los estados de emigración, tal como se ha hipotetizado en la literatura" (página 128). Sin embargo, en el libro no hay un análisis real del uso de las nuevas tecnologías por parte de los migrantes y sus impactos sobre sus modos de relación con la sociedad de origen 0 en su integración en la sociedad de recepción. Ello es algo a lo que debería dedicarse una mayor atención, y constituye uno de los principales puntos débiles del libro, en la medida en que los cambios tecnológicos se producen de manera cada vez más acelerada y afectan tanto a las poblaciones migrantes como a las poblaciones de los lugares de los que salieron éstas (las nuevas tecnologías de la comunicación han multiplicado la cantidad y la velocidad de los contactos, al tiempo que esta posibilidad también permite reducir la necesidad de moverse). Pero esta cuestión, abordada someramente, se convierte en una de las puntas de lanza en su denuncia de los excesos del transnacionalismo.

Muy crítico con el empleo de la perspectiva transnacional en los estudios migratorios, como ya mostró antes en su artículo "Beyond transnationalism" (2012), o en el otro artículo escrito junto a David Fitzgerald "Transnationalism in question" (2004), Waldinger vuelve a dejar entrever de nuevo su desconfianza con la efusión con que el transnacionalismo ha sido recibido en los últimos años entre numerosos investigadores. En el presente libro (capítulo dos) Waldinger retoma sus argumentos frente a la perspectiva transnacional y entra en un debate cuerpo a cuerpo con sus principales defensores, como el sociólogo Alejandro Portes (1999) 0 las antropólogas Schiller, Basch y Blanc-Szanton. A estas últimas, autoras del exitoso libro fundacional "Nations Unbound" (1994), les reprocha su excesivo optimismo en torno al comportamiento transnacional, a partir del estudio etnográfico de reducidas comunidades en "pequeñas islas caribeñas", afirmando que, "irónicamente, las autoras no han desarrollado un marco teórico ni un vocabulario conceptual para comprender la compleja trama de interacciones a las cuales dicen prestar atención" (página 18).

Las críticas de Waldinger se dirigen tanto a quienes confunden el transnacionalismo con el hecho de que la mayoría de los migrantes realiza alguna actividad transfronteriza, como a quienes se habrían centrado exclusivamente en estudiar a los migrantes que mantienen vínculos con sus lugares de origen, obviando a los que no lo hacen o lo hacen de un modo menos intenso. En esa misma línea, Waldinger también cuestiona la tesis de los entusiastas del transnacionalismo que sostienen que los vínculos de los migrantes se mantienen a pesar de su integración en el país de acogida (la tesis de Portes en torno a la compatibilidad de transnacionalidad e integración), destacando cómo los contactos telefónicos o los envíos se reducen progresivamente a medida que la instalación en el nuevo medio se prolonga. Igualmente, la idea de que los migrantes pueden mantener una vida por encima de las fronteras (vivir transnacional) es confrontada con las dificultades con que se enfrentan la 
mayoría de los propios migrantes. Para Waldinger, la posibilidad de convertirse en "transmigrantes" (a su juicio otra notable exageración) parece algo más bien reservado a una élite migrante que dispone del capital económico, social y educativo para poder desarrollar una vida basada en la movilidad y la comunicación permanente entre diferentes puntos del mundo.

Pese a que Waldinger reconoce algunos de los aportes del transnacionalismo, al poner de relieve las limitaciones del nacionalismo metodológico, así como su capacidad de alumbrar vínculos que muchas veces permanecen ocultos, también muestra las debilidades de un enfoque que habría sido encumbrado demasiado rápido a la categoría de teoría. La discusión entre si el transnacionalismo no es más que la descripción de la misma dinámica migratoria, 0 si contiene la envergadura conceptual y analítica para adquirir estatus teórico, se resuelve en la primera dirección. De acuerdo con Waldinger, la perspectiva transnacional permite ver los vínculos transnacionales, pero no ayuda a entenderlos.

Con todo, el libro no contiene solo una crítica frontal al transnacionalismo, sino que se extiende en otros ámbitos de interés para el análisis de las migraciones, como el papel jugado por los Estados de origen y destino o las mismas diásporas. Sobre la primera cuestión, Waldinger destaca las implicaciones políticas de la migración tanto para los Estados de origen como para los Estados de recepción (capítulos cinco y seis), que tanto pueden ejercer cierta protección sobre los migrantes, reconociendo por ejemplo algunos derechos, como provocar la desprotección sobre los mismos, generando zonas de sombra en las que éstos se hacen más vulnerables. En este sentido, la participación política de los migrantes sigue siendo uno de los asuntos pendientes para unos y otros Estados. Los Estados de origen ven a los emigrantes, en muchos casos, como sospechosos de desafección política por su abandono del país, tratándolos como disidentes. Por su parte, los Estados de recepción ven a los inmigrantes como una quinta columna de la que se duda de sus intenciones, por lo que su participación política tiende a dificultarse y postergarse. El resultado puede ser que la esperanza de gozar de los derechos de ciudadanía en el Estado de nacimiento y de los derechos políticos y sociales del Estado de llegada, se convierta en algo inalcanzable y que, más bien, lo que acabe produciéndose es una regresión en los derechos individuales de los migrantes. La dificultad de reclamar derechos a un Estado del que ya no se considera formar parte totalmente allí, y de hacerlo en un Estado del que tampoco se forma parte totalmente aquí, puede convertirse en un callejón sin salida que conduce a la degradación de las condiciones políticas de los migrantes. Al mismo tiempo, los intentos de los Estados de origen por establecer vínculos con sus ciudadanos en el exterior, pueden ser percibidos también por los migrantes como un intento de control de sus vidas, generando desconfianza respecto a las iniciativas que tratan de "involucrarlos" 0 , incluso, de "protegerlos", un hecho que ejemplifica a través del caso de la migración mexicana (capítulo siete).

Respecto al papel de las diásporas, Waldinger reserva un parte de su libro (capítulo ocho) a la discusión sobre el lugar de los migrantes en el desarrollo de las sociedades de origen. Sobre esta cuestión, que habría adquirido en los últimos años un lugar importante en la agenda de organismos internacionales y, en menor medida, de diferentes Estados de origen y algunos pocos Estados de recepción, el autor señala que este renovado interés por potenciar el papel de los migrantes como agentes de desarrollo no puede desligarse de la incidencia otorgada a las remesas como estrategia de desarrollo de los países de origen de la migración. A su vez, esta aparentemente bienintencionada propensión de los migrantes a ayudar a las poblaciones que no emigraron (lo que algunos han denominado "filantropía transnacional") no está exenta de conflicto e intereses cruzados: conflictos entre los migrantes y los Estados de origen que tratan de regular y encuadrar la acción de los primeros, y conflictos también entre los propios migrantes y las poblaciones que permanecen en los lugares de origen. Esta última apreciación en torno a la relación entre los migrantes y sus comunidades de origen permite a Waldinger introducir otro elemento de crítica al transnacionalismo, al destactar que las acciones de las asociaciones de migrantes no se dirigen a un conjunto nacional —lo que permitiría 
hablar con propiedad de transnacionalismo- sino a poblaciones determinadas por sus vínculos geográficos, e incluso étnicos 0 culturales, con quienes proveen la ayuda, lo que hace pensar más bien en una forma de translocalismo. En propiedad, lo transnacional debería comportar un nuevo escenario que transciende o recrea los límites nacionales, cuando en realidad lo que vemos es más bien la extensión de lo nacional más allá de las fronteras establecidas por los Estados. Lo nacional no queda diluido, ni es sustituido por una nueva construcción, sino que es desplazado geográficamente a uno y otro lado. Por tanto, en lugar de transnacionalismo lo que se produciría sería algo más próximo a un nacionalismo transfronterizo.

Como hemos podido ver, a lo largo del libro Waldinger nos propone una vía intermedia de comprensión entre la empobrecedora visión de los migrantes solo como inmigrantes 0 como emigrantes, y los excesos de quienes ven a los migrantes como "transmigrantes" que desarrollan sus vidas por encima de las fronteras, tratando de alejarse a su vez de la moda de anteponer el prefijo "trans" a cualquier supuesta novedad. La intención última del autor es proporcionarnos un nuevo marco teórico y conceptual para analizar las conexiones migratorias al margen del enfoque transnacional. En su afán por distanciarse precisamente de la perspectiva transnacional, Waldinger despliega un marco conceptual propio y alternativo, sustituyendo la noción de "Io transnacional" por "lo transfronterizo" y la de "campo social transnacional" por la de "zona de convergencia intersocietal", pero no anula la realidad descrita por los estudios transnacionales, con lo que tras la lectura del libro queda la paradójica sensación de que el autor logra finalmente explicar lo transnacional — la red densa de conexiones transfronterizas tejida por los migrantes- sin recurrir al transnacionalismo.

Las páginas escritas por Waldinger se convierten en una rica lectura que viene a alimentar el debate académico en torno a las migraciones, con un amplio despliegue de elementos tanto teóricos como empíricos. Sin duda, un libro polémico y sugerente, necesario para seguir avanzando en la limitada comprensión de las migraciones sin dar nada por supuesto y sin dejarse deslumbrar por las modas.

\section{BIBLIOGRAFÍA}

Basch, L., Glick Schiller, N., Szanton Blanc, C. (1994). Nations Unbound: Transnational Projects, Postcolonial Predicaments, and Deterritorialized Nation-States. Langhorne: Gordon and Breach.

Portes, A., Guarnizo, L. E., Landolt , P. (1999). The study of transnationalism: pitfalls and promise of an emergent research field. Ethnic And Racial Studies, Vol. 22 (2), 217-237.

Waldinger, R. (2012). Beyond Transnationalism: An Alternative Perspective on Immigrants' Homeland Connections. In Marc R. Rosenblum and Daniel J. Tichenor (ed.) Oxford Handbook of the Politics of International Migration. Oxford: Oxford University Press.

Waldinger, R., Fitzgerald, D. (2004). Transnationalism in Question. American Journal of Sociology, 109 (5), 1177-1195. 